\title{
Developing a Web 2.0-based system with user-authored content for community use and teacher education
}

\author{
Lauren Cifuentes $\cdot$ Amy Sharp $\cdot$ Sanser Bulu $\cdot$ Mike Benz $\cdot$ \\ Laura M. Stough
}

(C) Association for Educational Communications and Technology 2009

\begin{abstract}
We report on an investigation into the design, development, implementation, and evaluation of an informational and instructional Website in order to generate guidelines for instructional designers of read/write Web environments. We describe the process of design and development research, the problem addressed, the theory-based solution, and the evaluation and testing of that solution. Based on our experience, we then identify sixteen guidelines for future designers and developers of read/write Web-based learning environments. The study demonstrates how read/write Web technologies can be used to address general problems that have intrinsic societal importance; examines implementation of a read/write technology in a real-life context, thereby testing distributed cognitions learning theory; informs the design of similar environments; and provides grounded theory for the design and development of read/write Web learning environments.
\end{abstract}

Keywords Design and development research · Read/write Web · Web 2.0 . Distributed cognitions - Social constructivism

The emergence of read/write Web (Web 2.0) technologies such as wikis, Weblogs, Real Simple Syndication, Webcasts, and interactive photo galleries, has empowered users to actively contribute to the content of the Internet. By 2003, 44\% of adult Internet users had participated in the interactive capabilities of the Internet by posting in at least one read/ write Web environment (Lenhart et al. 2004). With so much activity initiated in such a short time, questions arise about the read/write Web's impact on educational processes. Some futurists and change theorists predict that as a result of Web-based user empowerment, a paradigm shift will take place in education of the magnitude of that created by the invention of the printing press (Graham 2004; Liu 2004).

L. Cifuentes $(\bowtie) \cdot$ S. Bulu $\cdot$ L. M. Stough

EPSY, CEHD, Texas A\&M University, College Station, TX 77840, USA

e-mail: laurenc@tamu.edu

A. Sharp - M. Benz

Center on Disability and Development, EPSY, CEHD, Texas A\&M University,

College Station, TX 77840, USA 
Richardson (2006) calls for researchers to identify ways in which instructors can take full advantage of read/write Internet capabilities to enhance learning for their students. In addition to elucidating how instructors can use read/write Web technologies for educational purposes, researchers need to provide evidence regarding how Web-based read/write environments might be designed and developed to serve intended audiences most effectively. Instructional designers and developers need models of how to harness the power of the Web and take advantage of its affordances to support collaborative knowledge construction. However, the literature on read/write Web technologies currently lacks guidelines for instructional designers and developers.

In this manuscript, we report on an investigation into the design, development, implementation, and evaluation of an informational and instructional Website in order to generate guidelines for instructional designers of read/write Web environments. We describe the process of design and development research, the problem addressed, the theory-based solution, and the evaluation and testing of that solution. Based upon our experience with this case, we then identify guidelines for future designers and developers of read/write Web-based learning environments. Process descriptions and findings are meant to inform instructional designers attempting to design Web 2.0 user-authored content for use in multiple settings.

\section{Design and development research}

A growing body of educational researchers argues that design and development research, also called design-based research, be conducted to bridge theoretical research and educational practice (Collins et al. 2004; Design-Based Research Collective 2003). Richey and Klein (2007) define design and development research as "the study of design and development processes as opposed to performing [those processes]" (p. xvi). Wang and Hannafin (2005) generated a descriptive definition and characterized design-based research as (a) pragmatic; (b) grounded; (c) interactive, iterative, and flexible; (d) integrative; and (e) contextual: "A systematic but flexible methodology aimed to improve educational practices through iterative analysis, design, development, and implementation, based on collaboration among researchers and practitioners in real-world settings, and leading to contextually-sensitive design principles and theories" (pp. 6-7). Such research generates usable knowledge about design and development of innovative learning environments and contextualized applications of theories of learning and teaching. Explications of design and development experiences in the real-world provide lessons-learned regarding instructional design, development, and implementation of learning environments and interventions in education.

Reeves (2000, p. 25) describes four steps to design and development research as a form of inquiry: (1) analysis of a practical problem by researchers and practitioners; (2) development of solutions with a theoretical framework; (3) evaluation and testing of solutions in practice; and (4) documentation and reflection to produce design-development guidelines. The goals of such design and development research are to generate guidance for designers and practitioners, as well as theory that is grounded in practice. The best guidance and theory generated from design and development research emerges from longterm collaboration among researchers and practitioners.

The research we report here is of design and development of an instructional product, a $\mathrm{read} /$ write Web-based environment that we call the Directory of Community Resources (DCR). As is typical in product development studies, we used documentation collected 
during the entire design and development process. Our process followed the tenets of instructional systems development, encompassing front-end analysis through evaluation (Richey and Klein 2007). The problem in this study was defined through needs analysis in an educational setting. An instructional environment delivered through read/write technologies was identified as the potential solution to the problem. Although the findings in this study are context-bound, the lessons learned may provide direction to other designers and developers who confront similar read/write Web development projects.

\section{The practical problem}

An ongoing challenge for individuals with disabilities and their families is gaining access to information about support services (McCarthy and Stough 2000). The Center for Disability and Development at Texas A\&M University was charged with addressing this problem through outreach to educators and service providers in the State of Texas to increase their disability awareness and then provide better service to people with disabilities. Needs analysis was conducted to identify specific goals, determine how well goals were already being achieved, determine the gaps between what existed and what was needed, prioritize the gaps according to agreed-upon criteria, and determine which gaps could be addressed through instruction (Morrison et al. 2004).

Needs analysis activities included a series of $60 \mathrm{~min}$ long focus groups at seven locations around the state with interested county agents and parents of children with disabilities. Focus group facilitators were staff of the Center on Disability and Development and the Texas Agrilife Extension Office. Participants took part in two focus groups at their location. Agents participated in an extension agent-only focus group while parents participated in a parent-only session. These focus groups were followed by a joint focus group with agents and parents. Focus groups' locations were selected to gain input from both rural and urban agents and parents. A structured interview protocol for agents, parents, and combined groups was used for data collection. Discussion probes were used to guide conversations. Focus groups were tape-recorded and later transcribed for analysis. A randomized table was created to assign researchers a designated transcript to code. Researchers were assigned to serve as primary coders for two focus group transcripts and to serve as secondary coders on another two transcripts. This ensured that themes were not overlooked by any individual conducting the coding. Hence, two separate researchers coded a transcript to increase reliability. If there was disagreement between the primary and secondary coder, a third coder was used. The transcripts were analyzed using a grounded theory methodology, developed by Strauss and Corbin (1990). Coded keypoints were grouped into similar concepts, in order to make them more workable. From these concepts categories of need were identified (Resch et al. 2009).

As a result of the needs assessment we set a priority for reaching out to educators in the public and private schools and colleges, and to county cooperative extension agents who are positioned to have a broad, positive impact on disability awareness. Although educators are usually well aware of the special needs of their students, this awareness typically does not extend to those who provide referrals to community services. County extension agents are one type of referral mechanism and provide information for local residents in workshops and seminars, at community events, through the media, and with a variety of information technology tools. In the case of this project we found that county extension agents received little training on disability issues and were limited, therefore, in their abilities to provide referrals to community resources. The mechanism for supporting the 
county agents' outreach, however, needed to be a directory of resources that was quickly and easily accessed on a just-in-time basis.

Although several directories have been developed and are available across the state of Texas, review of those directories revealed that they were neither comprehensive nor upto-date. The most broadly used online disability resource directory was last updated in 2001 so that much of that resources' contact information has been long since out-of-date. In fact, paper-based and Web-based directories are difficult and costly to maintain by a single institution because of constantly changing information regarding many of the resources.

\section{The solution framed in social constructivism and distributed cognitions theory}

In response to the need for a directory of resources, the Information Dissemination Coordinator of the CDD proposed that a read/write Website allowing the disability community to contribute and edit resources would be the most effective way to build, maintain, and sustain a comprehensive and up-to-date directory of disability resources. Such a site would serve counselors in schools and county agents to locate disability-related services in the state. While the initial intention was to develop a site that would be used by educators and county extension agents, we anticipated that the audience would extend to other referring agencies such as social workers or information lines, to direct service providers such as state agencies and non-profits, as well as to consumers of services such as parents and individuals with disabilities themselves. The goal of the site was to become comprehensive so that multiple users in multiple geographic locations across the state could use the directory in order to learn about disability-related services of most use to them. We conceived of this tool as one that would be continually updated and monitored by users as part of the CDDs mission to "... develop tools for better information dissemination to people with disabilities and their support systems." CDD staff believed that the promotion of the directory would help better serve its constituency as well as educate the disability community about the services available in the state.

In November of 2006, members of the CDD committed to building such a site, which was eventually called the Directory for Community Resources, or DCR ( http://disabilityresources.tamu.edu). If the DCR worked as planned, it would become a comprehensive, up-to-date, sustainable, and localized directory because of the read/write Web's affordances of allowing the entire user community to contribute and edit its contents. In short, we decided to harness the community to build the site that would facilitate broad disability awareness. Each resource entry would be collaboratively produced through negotiation regarding correctness, meaning, and relevance. In addition, if successful, the DCR would provide any and all online users, including the targeted audiences of teachers and county extension agents, with the information necessary to describe the types of services needed by people with disabilities, and to access information about available resources anywhere in the state. Service providers, educators, and users alike would be able to add resources to the DCR, edit entries of resources in the directory, and describe services that are available in urban and rural geographic regions or regions populated primarily by minorities. An important outcome of the site would be a clear representation of both what resources were available and what was lacking so that service providers and educators might identify gaps in services and supports for families. Once gaps were identified, service providers could then work toward filling them. 
Social constructivism, distributed cognitions, and read/write Web technologies

The systems for learning that are supported by the DCR and frame our solution to the problem of insufficient disability resource awareness are social constructivism and distributed cognitions. Social constructivism is an instructional philosophy most closely associated with the philosopher and psychologist Vygotsky (1978) and distributed cognitions is a learning theory proposed by Salomon (1994). According to social constructivism, meaning is culturally and socially influenced; simply put, the community around us affects the way we see the world. Today's social constructivists advocate for learning environments that are active, constructive, intentional, and cooperative, with students tending to work on performance-based activities such as collaborative problem-solving. Social constructivism is a critical tenet of engaged learning-where the learning community is energized by learning, by contributing to others' learning, and by personal responsibility for their own learning and contributions. Engaged learning features tasks that involve active cognitive processes such as creating, problem solving, reasoning, decisionmaking, and evaluation. Learning takes place in community: students participate in groups with flexible configurations, take on a range of individual and group roles (explorer, apprentice, teacher, producer), and seek different forms of support (mentoring, coaching, modeling, mediation) from instructors, their peers, colleagues, and other community members (Fosnot 1996).

Distributed cognitions theory follows from the philosophy of social constructivism and proposes that "knowledge is commonly socially constructed, through collaborative efforts toward shared objectives..." (Pea 1997, p. 48). According to the theory, intelligence is not solely an attribute within individuals, but is generated collaboratively within discourse communities. Tools in the physical environment serve as mediating structures that shape and direct human activity; and human activity emerges from human need. "Resources that shape and enable activity are distributed in configuration across people, environments, and situations [so that] intelligence is accomplished rather than possessed" (p. 50).

Read/write Web technologies in learning environments are particularly well suited to address a community's needs by supporting the accomplishment of intelligence. For instance, people with disabilities and their families have human needs for medical care, transportation, housing, etc. and have difficulty finding resources to meet those needs. By using a read/write Web-based tool in community they can socially redistribute their knowledge in order to inform each other regarding availability of resources, thereby enhancing disability awareness statewide.

Chen (2001), and Lightner and Willi (2007) suggest that when an educational goal involves evaluating, gathering, managing, and disseminating information, read/write Web environments are an excellent choice of medium. Such environments allow individuals to construct content on a Webpage as part of a shared knowledge base. In addition, instructors and learners can be social on the Web, both consuming and publishing Web content with ease. Learners publicly express their thoughts, respond to others' thoughts, post visuals, comment on those visuals, and even edit each others' files in shared online spaces. Surprisingly, although read/write Web environments allow multiple contributors and editors, researchers have found content on wikis to be both credible and authoritative. For instance, the information in Wikipedia was found to be more accurate than the information in the Encyclopedia Britannica by Butler et al. (2005). In short, everyone together is smarter and more accurate than any single person. In a well-publicized study, Halavais and Hernandez (2004) intentionally created thirteen errors in Wikipedia and then sat back to watch what 
happened; it took just 2 hours for his errors to be fixed by the reading public. In wikis, soft security is conducted by the user community.

Rapid collaborative prototyping in instructional design and development

The approaches to development of the DCR were user participatory design (Carr 1997) and rapid prototyping (Dorsey et al. 1997; Jones and Ritchey 2000). Following this approach, designers collaborate to create multiple iterations of instructional materials using continuous cycles of conceptualizing $\rightarrow$ building $\rightarrow$ user testing. Designers present each prototype to a sample from the user community and "the prototype encourages communication between everyone concerned with the effort" (Jones and Ritchey 2000, p. 67). Communications inform design. Gustafson and Branch (1997) place implementation at the center of these cycles as the mediator of analysis, design, development, and evaluation activities:

Rapid prototyping usually involves quickly creating a general sense of what the goal is and only limited design specifications. This is followed by rapid (and low cost) development of a prototype that contains at least some of the operational features desired in the final product. Then, through a rapid series of iterative tryout and revision cycles the product is shaped until an acceptable version is created... The product is continuously refined and enhanced (p. 84).

The importance of user input is accentuated when designing read/write Web environments because the contents of such environments are constructed in large part by users after an environment has been designed. When rapidly prototyping the DCR, we based each iteration to a large degree on user input. The vast majority of user input involved suggestions for improving the usability of the interface. Other suggestions included ways to make the site more aesthetically attractive, ways to make resource categories more inclusive, and ways to identify of technical bugs in the program. Early development and continuous evaluation of prototypes with stakeholders ensured that the needs of stakeholders would be met and that users would contribute to, and to some extent maintain the contents of the Website.

The greatest strength of the read/write Web environment is the ability to harness the community so that the site grows and remains up-to-date with ever-changing data. Read/ write Web technologies allow the broad community to maintain a comprehensive, localized, and up-to-date directory.

Two conditions assure that our project exemplifies a class of Web 2.0 projects: first, the DCR has interactive, read/write capabilities, and second, success of the Website depends on a broad user communities' motivation to make and edit contributions. As with other Web 2.0 sites, this site has multiple missions of information gathering, information dissemination, and providing for learning about the topic of the site itself. This site may differ from other Web 2.0 sites in that the developers had a relaxed development timeline, a community service and instructional orientation, and limited development resources.

\section{Evaluation and testing}

Lessons learned during the two-year development process informed the authors and led to the generation of supplemental guidelines for the rapid prototyping of other read/write Web environments for use in instructional settings. We asked the following evaluation 
questions repeatedly during design and development team meetings and the answers guided research and development activities: How is the DCR being developed and used? What problems arise as we develop the DCR? What resources are needed? What problems do DCR users have with navigation, accessing resources, contributing resources, or editing resources? How effective is the read/write Web-based environment as an outreach tool? How effective is the read/write Web-based environment as a learning tool for county agents, special educators, and people with disabilities and their families? And, what design-development guidelines can we propose based on our experience in designing and developing this environment? Answers to these questions were recorded in design documents after each meeting.

\section{Evaluation design}

The researchers used formative evaluation as the research method, continuously investigating the DCR in pursuit of establishing design and development theory grounded in experience (Orrill et al. 2003; Wang and Hannafin 2005). In design-based research such as this, researchers hybridize instructional design methods with research methods as they investigate their own processes. In this case, the researchers collected data from design documentation, the lead designer's journal, Google Analytics reports of ongoing use, usability surveys, interviews, and user focus groups.

Several researchers have enumerated the limitations of design and development research that may reduce the credibility and generalizability of the resulting design guidelines. For instance, Dede (2004) expressed that, standards for judging the effectiveness of a particular design such as for the DCR do not exist because instructional products are localized and unique. Thus, establishing the validity of design principles remains questionable. In addition, because researchers simultaneously act as evaluators, some bias must be assumed (Wang and Hannafin 2005). Furthermore, as the data collected are extensive, somewhat repetitive, and comprehensive, much is typically discarded in the interest of time and resource management (Collins et al. 2004).

The DCR team attempted to overcome these limitations and enhance credibility and generalizability of findings by collecting data continuously, triangulating data with multiple sources, and considering perspectives of multiple participants. They also conducted member-checks to ensure agreement (Lincoln and Guba 1985) before drawing conclusions. In advance of the study, the researchers planned research activities according to Wang and Hannafin's (2005) nine principles central to design-based research to inform planning and implementing technology-enhanced learning environments. First, the designers/researchers analyzed available literature on Web 2.0 technologies for information dissemination and education as well as theories that underpinned the purposes of the design. Second, the team set practical goals for theory development and developed ongoing plans. Third, the study was conducted in the natural work environment over two years and included continuous input from a team of CDD staff who were dedicated to increasing disability awareness in the state of Texas. Fourth, the team collaborated closely with participants. Fifth, research methods were implemented systematically and purposefully. Sixth, as the team collected data, those data were analyzed immediately, continuously, and retrospectively. Seventh, the team continually used data to refine the DCR design. Eighth, the team developed design-development guidelines based upon authentic design experiences. And, ninth, the researchers validated the design guidelines with the development team and users to establish their generalizability. 
Participants

The Information Dissemination Coordinator of the CDD also served as lead designer and researcher of the DCR. That researcher managed processes in collaboration with all other participants. During most of the development process the core design team met weekly when possible. It consisted of the lead designer, two content experts, and a Web developer. Since the technical skills required to develop the site shifted after one and one-half years, the Web developer changed. The CDD staff served as content experts and Website evaluators bi-weekly in the first year and monthly in the second. Undergraduate and graduate level students in university special education courses contributed resources to the DCR as part of their coursework and filled out contributor surveys. On two occasions an expert on accessibility evaluated the site. Several user groups from the disability community evaluated the site by filling out surveys or participating in focus groups.

In addition to those participants providing evaluation data, several groups were solicited to help build the site by making contributions and updating resources. Letters went out to special education faculty, public school Regional Service Centers, and various nonprofit organizations around the state informing them of the DCR's Web presence and suggesting that they add resources to the site (see Table 1).

Data collection and analysis

The lead designer kept a journal that included lessons learned during design and development processes. Documentation was constructed weekly. Google Analytics reports of ongoing use were regularly examined as indicators of successful outreach as measured by use. Questions about content, design, technical quality and use were delivered in multiple usability surveys, interviews, and focus groups with a variety of audiences during the two years of design and development. Data was summarized in a continuous record of design issues, tasks to be done, task due dates, responsible party, and task status.

Table 1 Participants

Core design team

Design team

Intended users

Those assigned to contribute resources

Evaluators
CDD Director, Information Dissemination Coordinator, and Associate Director, website developer

The core design team and 8 other CDD staff

County extension agents, special education and classroom teachers, school counselors, disability service providers, people with disabilities and their families

Undergraduate and graduate level special education students

CDD staff including: Communication Specialist, Public Policy Coordinator, Texas AgriLife Extension Service Liaison, Interdisciplinary Training Coordinator, Research and Evaluation Coordinator, and 3 Center Fellows; Undergraduate and graduate level special education students; The Association of University Centers on Disability; The Texas Department of Aging and Disability Services; The Autism Council; The CDD Advisory Council; Higher education special educators; A group at the Texas Transition Conference; Disability Services Texas A\&M University; Texas Project First; The Disability Policy Consortium; Texas Council for Developmental Disabilities; and a sample of special educators at Texas Region Service Centers 


\section{The development story: how was the DCR developed and used?}

Once the need for a state-wide resource directory was established, I, as the CDD dissemination coordinator identified functionality and usability needs of such a directory. I compared the affordances of those functionality and usability needs with different technologies and decided to suggest adoption of wiki technology to the CDD team. The rationale was to provide for community participation in rapid population of resources on the directory. With a graduate student of instructional design, I developed several paperbased thumbnail sketches of possible interface designs.

Because Texas is geographically big with a large population, the graduate student and I quickly realized that we needed to include some kind of geographical organization. We considered several alternatives for dividing Texas into regions. One idea was to list resources for each county, but this was impractical with 254 counties: Some counties had no resources and some metropolitan counties had hundreds. Another idea was to use the regions established by the Texas Education Agency so as to disseminate the site through their service centers. The CDD staff and members of its Advisory Board recommended including at least one major city in each region. Ultimately, to meet recommended criteria, the team decided to organize the resources according to regions established by a CDD partner, Texas AgriLife Extension Service, which serves Texans through community-based education programs.

Category of need for people with disabilities and their families was the second organizing construct for the interface. For the previous five years, one of the CDD faculty had given an assignment to her students to develop a Web and paper-based directory of local services for individuals with disabilities. In the context of that assignment, students systematically investigated available services for individuals with disabilities and their families. After several years of collecting these resources, the faculty member and her graduate student developed a taxonomy that used fifteen categories of service needs in order to organize the resources that had been located in the surrounding county. We chose these categories to represent functional needs such a employment, transportation, education, etc., so that individuals with disabilities and their families could locate services given their particular support needs, rather than using a medical-model which uses diagnostic categories of disability. The CDD staff similarly decided to adopt those validated categories for organization of the directory.

After creating paper prototypes using the 12 Texas regions and the 15 service categories as the organizational structure, the designers decided to create a Web-based prototype. We considered several factors including flexibility, available of tools, security, and cost when exploring various freeware wiki applications. This led us to adopt PmWiki as the software for development of the initial prototype presented to the staff during a team meeting.

PmWiki is a WikiWikiWeb clone developed in PHP programming language. It has been primarily designed as a tool to support easy, collaborative authoring and maintenance of Web sites. The software comes with several interface templates and is configured for easy interface modifications. Using paper prototypes as templates, quick interface prototypes can be developed. Since we used a functional software package for our prototypes, we had significant functionality from the beginning, enabling us to test our design ideas and the overall usability and functionality of the directory with the CDD staff from the start.

Once the CDD staff accepted the idea of developing a directory, the CDD director created a design-team from the CDD staff. The team tested the prototype's functionality with five different individuals from the CDD Advisory Council one-on-one using a thinkaloud protocol. The individuals were two adults with disabilities and three parents of 
children with disabilities. They were asked to locate resources on the site, contribute a resource to the site, and edit an existing resource on the site. The prototype had a Texas map with 12 regions on the homepage; within each region was a categorized list of resources. After this testing the team revised the prototype in many ways including adding fields for more specific descriptions of resources such as whether they were non-profit, profit, or cost for service; adding hot links from resource descriptions to resource Websites; adding "contact name" as a resource field, naming counties as users roll over them with the mouse; and simplifying our category descriptions which were previously too jargon laden and lengthy.

We then field-tested the DCR using undergraduate college students and graduate students in two different classes. We made several changes based on their feedback. For example, we added a list of major cities in each region to our homepage. We then sent a mailing to region service centers and to forty-six special-education college faculty around the state informing them of the site and inviting them to have students and teachers use the directory to locate, contribute, and edit resources to the DCR.

During the first year of DCR development, we met with eleven groups from the statewide disability community and one national organization, The Association of University Centers on Disability, to formatively evaluate the site and to encourage use as well as contributions to the site. Since the CDD has organizational partnerships and relations with statewide disability groups, we promoted the DCR to those groups and considered their suggestions in the design of the directory.

After a year and a half of use, the DCR had grown to contain approximately 3,600 resources. However, even though hundreds of people had been invited to contribute, the broad learning community was not contributing or editing resources to the site to the degree that we had hoped. For instance, only two faculty members beyond our institution had adopted contribution to the DCR as a course assignment. Students in our institution expressed frustration with the length of the directions and amount of html required to make entries. Few entries were made beyond those elicited by direct contact from design team members.

But, for the DCR to be successful, the community had to be involved in its construction and maintenance. Formative evaluation data indicated that even with clear and simple directions the html requirement for making entries in PmWiki was limiting community participation. At that time, the team decided to transfer content of the DCR to a site that we designed in Drupal software which would allow community members to contribute and edit entries using forms.

Drupal is a free and open source modular framework and content management system (CMS) written in the programming language PHP. Like many modern CMSs, Drupal allows the system administrator to create and organize content, customize the presentation, automate administrative tasks, and manage site visitors and contributors. (Drupal 2008)

The transfer process took approximately 300 human resource hours. It involved establishing the Drupal site, simplifying the interface, designing forms, transferring and checking the validity of each resource, and adding a calculator of approximate distance between the user and any given resource. Given the collaborative nature of the contents of the site, we placed the following disclaimer at the bottom of the home page: "The Directory of Community Services is a project of the Center on Disability and Development ... We cannot guarantee the accuracy of the information included in this directory; however, we trust that 
users will make every effort to manage their own information with integrity to the entire community's benefit."

\section{Findings}

Problems that arose as we developed the DCR

During the development process, creating an intuitive interface to facilitate resource entry and maintenance was the constant concern. We had to continually ask: "what is the best way to collect and display content in order to encourage use as well as protect the site." Secondly, duplicated entries and entries such as a description of a local MacDonald's which included no disability-related information popped up in the environment, making surveillance important. A third problem involved resistance to community-generated content. We had to develop promotional materials and explanatory documents that would convince resisters to support development despite their concerns. Fourth, as we initiated development, we did not yet know what technical and human resources would be required to complete design and development; therefore, it was difficult to establish a budget for the project. Finally, content on the DCR depended completely on use by the community, and, reciprocally, use depended upon rich content. We therefore needed to develop marketing strategies and continually nudge the community to contribute, even with early, difficult-touse prototypes that had limited resources posted to them.

\section{Resources needed}

We developed early prototypes with few resources. Beyond the team of human resources needed to generate ideas for the design and provide skill in Webpage and database development, only a Website server and application of the freeware, PmWiki, were needed during the first year of the project. Similarly, in the second year of development, the freeware, Drupal, was applied to manage, edit, and report outcomes of the site. Zipdy, a free program for calculating the distance between two zip codes, finds all the records with a zip code within $\mathrm{x}$ miles of another zip code. Zipdy was written in $\mathrm{C}$ but is also available in PHP and perl (September 2008; http://sourceforge.net/projects/zipdy/).

\section{Problems for users}

As problems arose for users, the development team discussed and attempted to solve each problem through better design. Some students were initially intimidated by PmWiki's requirement for minimal use of html; they had to print out and follow somewhat complicated directions to make or edit entries. In addition, users did not like the way their entries looked in the PmWiki environment. It was problems like these that led us to develop straight-forward forms in the Drupal environment.

\section{Effectiveness of the read/write Web-based environment for outreach and learning}

The objective for users of the DCR was simply that they be able to access much needed resources and find help in a timely fashion. However, the objectives for contributors to the DCR extended beyond simple access to information. As they constructed the DCR 
together, special education students reported that they learned to (a) describe the types of services needed by people with disabilities, (b) describe systemic services that constitute best practice, (c) describe services that were and were not available in urban and rural geographic regions or regions populated most by minorities, (d) generate ways that they as educators might fill gaps in services and supports for families, and (e) evaluate the effectiveness of a resource, determining what is worthy of being posted to the DCR. They enjoyed learning by studying, using, and contributing to the DCR. They found the content to be accurate and applicable to the curriculum and found making directory entries straightforward. They considered the graphical interface to be attractive, bug-free, and effective.

Use reflects effectiveness as an outreach tool. Google Analytics gave use information for any given time period (hours, days, months or years) about overall and specific hits of the Directory. Table 2 summarizes the DCR usage statistics when PmWiki software was used. During the first year, when the DCR was created in PmWiki, 8,333 visitors visited the site and viewed 68,884 DCR pages. These numbers indicate that the site engaged users to the extent of viewing an average of 8 pages once they arrived at the site. The time periods when users added or edited resources most correspond to those when faculty assigned DCR updating to students. The visibility of the site outside Texas may indicate interest in replication for other states. From June to September of 2008 we shut down the contribution and editing capabilities as we transferred the content to the Drupal site. Therefore, there are no data on those functionalities while the site was dormant.

We reinitiated contributing and editing capabilities for users in the Fall of 2008. After two months the site had been visited by 4,172 users who viewed 22,066 pages — an average viewing of 5 pages even though the team had not assigned activity in the DCR to student users that semester. The initial posting of the new version of the DCR initially had fewer users' actively adding and editing resources. However, those numbers are growing as the broad community becomes aware of the site (see Table 3).

The DCR's contribution to disability awareness

The DCR was used in school district and region service centers, in college-level special education courses, and in the Disability Awareness module on the Texas Agrilife Extension Service's Website which is received by hundreds of county extension agents and

Table 2 Directory usage statistics when PmWiki software was used

\begin{tabular}{|c|c|c|c|c|c|c|c|}
\hline & \multicolumn{7}{|c|}{ Time period } \\
\hline & \multicolumn{4}{|l|}{2007} & \multicolumn{2}{|l|}{2008} & \multirow{2}{*}{$\begin{array}{l}\text { Total } \\
07-08\end{array}$} \\
\hline & $\mathrm{J}-\mathrm{M}$ & A-J & $\mathrm{J}-\mathrm{S}$ & O-D & $\mathrm{J}-\mathrm{M}$ & A-J & \\
\hline Total number of visitors & 335 & 590 & 630 & 1541 & 2628 & 2609 & 8333 \\
\hline Pages viewed & 6213 & 16861 & 6891 & 14703 & 12004 & 12212 & 68884 \\
\hline Edits & 357 & 1283 & 233 & 667 & 174 & 129 & 2886 \\
\hline Resource adders & 28 & 66 & 16 & 38 & 9 & 7 & 164 \\
\hline Users who edited & 36 & 71 & 22 & 83 & 22 & 18 & 252 \\
\hline Users of search engine & 40 & 150 & 361 & 974 & 2015 & 2044 & 5584 \\
\hline Users from United States & 317 & 567 & 594 & 1487 & 2451 & 2514 & 8011 \\
\hline Users from Texas & 283 & 497 & 444 & 1183 & 1994 & 2024 & 6425 \\
\hline
\end{tabular}


Table 3 Directory usage statistics after the use of Drupal

\begin{tabular}{lrrr}
\hline & \multicolumn{2}{c}{ Time period } & \\
\cline { 2 - 4 } & September 26-October 31 & November 1-December 3 & Total \\
\hline Total number of visitors & 1840 & 2332 & 4172 \\
Pages viewed & 12058 & 10008 & 22066 \\
Edits & 51 & 29 & 80 \\
Resource adders & 19 & 10 & 22 \\
Users who edited & 50 & 14 & 53 \\
Users of search engine & 746 & 1487 & 2233 \\
Users from United States & 1811 & 2267 & 4078 \\
Users from Texas & 1595 & 1934 & 3529 \\
\hline
\end{tabular}

administrators. Graduate students in special education reported that working on the DCR improved their awareness of person-first language, of the needs-centered definition of disabilities, of the presence of resources in certain regions, and of the absence of resources in others.

\section{Discussion and design-development guidelines}

As we reviewed findings and revised the Website accordingly, themes emerged in the data: prototyping, user-based design, human-computer interaction, and technical issues. These themes provide the categories for our recommended approach to designing read/write Websites.

\section{Prototyping}

When introducing the idea to decision makers, develop an initial rough Web-based prototype (rather than paper-based) to demonstrate the application to those unfamiliar with the functionality and potential of the read/write Web

Before the read/write Web was available as a medium for instruction, rough prototypes were used during instructional development simply as models of a proposed solution. As such, they were assumed to represent an adequate proxy for the solution; a close resemblance to the final instructional product was not required. For instance, paper-based story boards were an acceptable medium for evaluation of instructional materials. According to Jansen and Smith (1985), with low-fidelity prototypes "neither the form nor the materials used in [a prototype's] construction have to be those of the final design, as long as the basic idea or concept can be tested" (p. 306). "Fidelity" here means the degree to which the prototype matches the full functionality and provides the look and feel of the intended final product.

In today's world of pervasive computing, however, we found that some CDD staff and users participating in the development process were looking for a graphically slick product from the start. They were helpful critics of the graphical interface, navigation processes, and functional aspects of the site, but were not willing to commit to the project until they had seen a prototype that closely resembled the final instructional product. 
Thus, when developing with Web 2.0 technologies, at this early point in the history of the technology, decision makers may need to see the functionality to fully understand it; and solicited adopters need to see what is being proposed. Therefore, we suggest that rough prototypes be made and presented on the Web. At the time that the DCR was first proposed (November 2006), each of the staff members of the CDD indicated lack of familiarity with wiki technology and wanted to see the functionality in order to envision the site's potential. Our rough but functional prototype convinced critical team members that the DCR might solve the problem we were charged to address. This persistence paid off as we presented the rationale for the environment to a broad audience and argued for its unique contribution.

\section{Rapidly populate the site with a critical mass of entries}

To function as intended, read/write sites need user contributed content. Because an early functional prototype is critical for illustrating the power of read/write Web technologies and gaining user buy-in, developers need to identify users who can be harnessed to quickly populate the site and demonstrate the power of community participatory collaborative development. Without resources on the DCR, that site could not be perceived as useful. For the DCR, the contributions of students in both undergraduate and graduate level classes added hundreds of resources within the first weeks of DCR development, and those contributions facilitated buy-in from stakeholders.

\section{Explain the concept of the rough prototype to users to get them on-board with shared design tasks and gain quality feedback during early stages of design}

Such an explanation is quite necessary. Otherwise, the low-end presentation and functionality of early prototypes coupled with slight contents may diminish stakeholders' and decision makers' interests. Dorsey et al. (1997) suggest employing "low fidelity prototypes to gain quality feedback during early levels of design" and "high fidelity prototypes to gain quality feedback during final levels of design" (p. 452). A prototype is effective when the user can see at least a rough approximation of the interface, navigate the site, and explore its functionality and content in order to give constructive feedback.

\section{Be willing to tolerate even lower-fidelity designs as you respond to the team and gain} acceptance through collaborative design efforts

Team members must know that design of the site is a team effort and that all voices are respected. This requires continuous response to issues in an iterative series of prototypes as proposed by stakeholders. If you have no convincing rationale for not following a particular design suggestion, it may be in the best interest of the initiative to adopt a less functional design. However, while making any changes that will certainly improve the function or substantive value of the environment, you should take advice cautiously. Including the broad community will lead to a lot of advice, some of which will be contradictory and/or conflict with what you know about good design. In order to gain buy-in from the community of users, and particularly from funding sources, you will need to compromise at times. In our case, data from usability studies helped us to identify design strengths and weaknesses and ultimately informed a highly functional design. 
Make modifications and post revisions quickly so that team members, users, and stakeholders can see the impact of their input

We continuously modified, making weekly meetings and regular input from stakeholders worthwhile for all concerned. Such prompt modification allows users to know that their needs and perspectives are taken seriously.

User-centered design

Continuously involve a broad range of stakeholders from the user community in design decisions and regard them as designers

Read/write Web technologies extend the involvement of stakeholders in the design of instructional environments into the diffusion stage of instructional development, granting more power to those stakeholders than was ever before possible. Stakeholders go beyond simple involvement in identifying necessary design features; they actually apply design features to enter the content, thereby establishing the criticality of user input on the functionality of a read/write Website. With read/write Web technologies, design and diffusion can happen simultaneously. Since user involvement in building site content depends on ease of use, ease of use must be established during the design and development processes (Carr 1997).

\section{Systematically record each suggestion and consider how to respond}

Some design ideas contribute to a higher functioning prototype, and those ideas should be implemented. Many other suggestions will be repetitive, technologically unfeasible, or excessively complicated; but all suggestions should be considered. In our experience, we found that each suggestion reflected a positive wish for the DCR to provide a community service. "Deceptively simple suggestions may conceal a variety of needs. Solution propositions must be critically examined, no matter what the source" (Dorsey et al. 1997, p. 451). Again, consider each suggestion, but take advice cautiously.

\section{Apply strategies of change agency}

This guideline may be the most critical of all for read/write Web development. User-based design activities and product-adoption, as described above, depend upon buy-in from various stakeholders. Because read/write Web technologies offer a different approach than prior technologies to information collection, validation, and dissemination, we recommend that at least one member of the design team act as a change agent. The change agent's role is to facilitate the transformation in fundamental philosophy of education required during the analysis, design, development, implementation, and evaluation activities. In this case, the very strength of the technology limited outright acceptance of the read/write Web technology. Leaders and decision makers in the disability community naturally hesitated to openly invite the world of stakeholders to contribute to and edit the site. They were, of course, concerned that hackers or spammers might pollute or degrade it.

Most people, when they first learn about the wiki concept, assume that a Website that can be edited by anybody would soon be rendered useless by destructive input. It sounds like offering free spray cans next to a grey concrete wall. The only likely 
outcome would be ugly graffiti and simple tagging, and many artistic efforts would not be long lived. Still, it seems to work very well (Aronsson 2002, p. 31).

Project staff expressed values of teamwork, respect for community members, inclusion, sharing, and collaboration. Nevertheless, many team members' approaches to DCR development were characterized by skepticism. Knowledge of change agency processes helped the team to transform stakeholders' negative views about the technology so that they could commit to harnessing the collective knowledge of the disability community.

To facilitate adoption, a rough Web-based prototype of the DCR was constructed in preparation for proposing development to the CDD staff of ten. The DCR met six of Ely's (1990) eight "conditions for change," suggesting that the time was right for adoption of a $\mathrm{read} /$ write Web environment: (1) there was dissatisfaction with the status quo regarding disability awareness on the part of service providers, (2) people who would ultimately implement the DCR possessed sufficient skills and knowledge to make it function, (3) Web environments have become widely accessible across the disability community, (4) time could be dedicated to development and dissemination, (5) the rewards and incentives for adoption were evident once explained, and (6) support for broadening disability awareness was both expected and encouraged.

When first proposed, this innovation immediately met resistance from seven of the eleven CDD staff members. During and following that meeting, the Information Dissemination Coordinator acted as the change agent for dealing with resistance at every meeting involving DCR design and development. The seven strategies for conveying an innovation to intended users were care, relate, examine, acquire, try, extend, and renew (Havelock and Zlotolow 1995, p. 2). Approaching the project with an attitude of caring and inclusiveness and a strategic plan for continuously evaluating the impacts of the problemsolution convinced stakeholders of the value of the project. The result of active change agency was that by the end of the first meeting the leadership demonstrated guarded acceptance by requesting a more refined proposal to address the staff's concerns. At that point, to a minimal but critical extent, the innovation had met Ely's last two conditions: (7) go-ahead and vocal-support by key players and other stakeholders, and (8) necessary buyin on the part of leadership to support moving the innovation forward.

During development of the DCR, each of Havelock's seven strategies was applied on an as-needed basis regarding the prototype under evaluation at that time. Because of the expressed need and the altruistic quality of the DCR, strategy one-caring about the project-was easy. However, the admonishment to "first do no harm" expressed by resistant stakeholders had to be considered. Spector admonishes that-

While there is a rich variety of work to be done by instructional technologists and many different kinds of instructional technologists, the creed of instructional technology might well be a variation of the physician's Hippocratic oath: (1) do nothing to impair learning and instruction; (2) do what you can to improve learning and instruction; (3) base your actions on evidence that you and others have gathered and analyzed; (4) share the principles of instruction that you have learned with others; and (5) respect the individual rights of all those with whom you interact. (Spector 2005, p. xxxvi)

In read/write Web technologies there is no guarantee of avoiding harmful intrusions altogether. Therefore the team developed and communicated the means for minimizing risk. We opted to protect the site by requiring a logon protocol for making contributions and edits and, to maintain the power of read/write Web capabilities, allowing anyone to 
establish a logon ID and password. Strategy two, relating, also proved quite easy as, once the development process was underway, an active team met weekly over the course of two years. Members of the team were broadly connected to various stakeholders and could facilitate collaboration among members of the stakeholder system.

Havelock and Zlotolow's strategies examine, acquire, and try involved data collection regarding our solution. This was conducted continuously during prototyping as the site was almost constantly up and running on the Web and the team continuously tested its feasibility resulting in positive findings. Users involved typically committed to the DCR and determined that it would benefit the disability community for a relatively low cost. The DCR was viewed as practical; and, given its demonstrable benefit and workability, was thought by the design team and the disability community to be accepted by enough members of the community to be sustainable. The disability community expressed that the DCR was a solution to a problem. Each step in the development process was informed by multiple voices, and all revisions were based upon reactions to prototypes by users or the design team.

Currently, the project team's efforts are toward strategy five, the extension of the innovation into the broad community to solidify adoption, defined as "gaining deeper and wider acceptance" (Havelock and Zlotolow 1995, p. 125). Several initiatives advance this effort including customized email messages sent out regularly to all current resource entry organizations (approximately 4000), special education faculty around the state, school region service centers, agriculture extension agents, government agencies, and service organizations. In addition, we promote the DCR through CDD newsletters, brochures, and conference presentations. Each meeting, focus group, or interview facilitates renewal in the DCR.

Human-computer interaction

\section{Consider potential multiple functions of the site, and design to support those functions}

Although read/write Web environments may be designed with a specific audience in mind, they are often publically distributed and are therefore open to use for any number of purposes. We initially conceived of the DCR as an outreach tool for county extension agents, but during design its functions extended to the broader community; in fact, its name in the second prototype was "The Directory of Disability Resources for People with Disabilities and Their Families," and its functions were to quickly gather, manage, and disseminate disability resources to all interested parties statewide. As described above, the DCR also functions as a learning-tool to build awareness in special education students regarding resource availability and geographic distribution. For a time the DCR included a discussion forum so that students could post their insights regarding resource availability as they contributed to the site. Although, the forum is no longer on the site, designers are considering reinstituting it as feedback from university student participants has indicated interest in such a discussion.

\section{Identify what attracts members of a community to use the Web environment}

Thus far, most users, and an increasing percentage, have found the site through a search engine; almost half of the users were referred to the site through conferences, organization meetings, or mailings (see Tables 1 and 2). As ease of use improved, use increased. In early prototypes, some users were unsuccessful at locating, contributing, or editing resources and therefore did not adopt the site. In later prototypes, when students 
experienced success, they expressed interest in using the site often and referring others to it. With the ownership afforded to users by the read/write Web comes increased interest. Search engines, referrals, ease of use, success at finding useful resources, and ownership all attract members of the community to the DCR.

\section{Identify barriers that interfere with interest in making contributions and put forward effort to overcome them}

When we asked why survey respondents did not contribute resources to the site, most said that they did not know they could. Because the capabilities of read/write Web technologies are new, many people still do not expect to be able to contribute or edit content. We have made an effort to educate the disability community regarding Web 2.0 affordances. Additional barriers to making contributions are the time and effort that it takes to know all the information about a given resource in order to fill in required fields.

\section{Facilitate use, contribution, and editing by creating favorable conditions through functional design}

"Visual design attempts to solve communication problems in a way that is at once functionally effective and aesthetically pleasing" (Mullet and Sano 1995, p. 1). Better quality of graphic design of the Website significantly improved its communicative value, leading to increased usability. Graphic conventions for logging on; searching by keyword, category, zip code, and location; and entering information in forms were applied to the DCR in the hopes that they would facilitate efficient and easy use and positive experiences on the site. The highly structured form for entries makes entry and editing of content easy.

Technical issues

\section{Develop a plan to protect the site's content}

Three types of maintenance are needed for the DCR. One is maintenance of the software on the server to ensure security and efficiency, and the second is backing up and editing directory content to ensure safety and accuracy. The DCR software is updated and backed up daily. Optional functionalities include password protection, discussion boards, responsive comments, or different styles and formats. Keeping the software up-to-date and bug-free is essential to avoid security problems and software errors. Since there is always the possibility of losing DCR content due to uncontrollable server problems, it is important to backup directory information that is continuously updated by users. In addition, the system should be managed to eliminate spam, provide for better user experience, and control information accuracy. A third way of protecting the site is to instill community ownership in users so that they feel responsible for actively maintaining the site.

\section{Begin prototyping with data-based software rather than wiki technology}

To avoid duplication of efforts and transfer of large data sets, rather than beginning with unsophisticated wiki software as we did, begin development in a data-based software such as Drupal. This guideline requires Website development skills or funds to pay a Website developer. 


\section{Employ a skilled programmer to develop the prototype}

This is self-explanatory but must be mentioned because of the complex programming involved in development of such a Website.

\section{Apply strategies to move the Website up in listings created by search engines}

Our outreach goals depended upon participation by the broad community. Therefore, it was critical that the site be listed by search engines, picked up by keywords, and appeared high in search engine rankings. We applied several strategies that led to broad dissemination through search engines (Descy 2007). First, we created a descriptive title for the site and inserted appropriate title, description, and keyword metatags. Second, we urged users to link to the Website from their Websites because search engines list sites in large part according to the frequency with which other sites link to them so. Third, we added the site to Google (www.google.com/addurl/) and Yahoo (siteexplorer.search.yahoo.com/submit). Fourth, we marketed the site through email, snail-mail, and conference presentations to encourage use which leads to higher rankings.

\section{Conclusions}

The DCR content has been and still is being constructed by advocates, local experts on disability throughout the state, and university students in the context of course assignments. Multiple goals are served when individuals construct meaningful products such as the DCR with members of a community. First, the acts of investigation and contribution can promote the contributor's learning. Second, the act of contribution fulfills individuals' altruistic aspirations. Third, each contribution improves the efficiency and effectiveness of service providers in their future work day. And fourth, a broad audience benefits from access to the contents of the collaboratively constructed product. Entering just one resource benefits the community as a whole and may help any number of people in need. In read/ write Web environments, the learning product is a contribution beyond the self. That product lasts long beyond the moments of production and publication because it remains on the Web to benefit the community for an extended period of time.

This study is significant in several ways. First, it demonstrates how read/write Web technologies can be used to address general problems that have intrinsic societal importance. Over the years educational research has been criticized for having little practical relevance. Reeves (2000) calls for socially responsible design and development research that addresses relevant, real-world problems. Our study provides an elaborate illustration of the process for conducting such research in the field of educational technology and instructional design. The product under study, the DCR, stands as a solution to substantial societal problems of lack of disability awareness by service providers and an established lack of access to resources by people with disabilities and their families.

Second, the study examines implementation of a read/write technology in a real-life context, thereby testing distributed cognitions learning theory which suggests that a community of users will be best served by a site when the community has the opportunity to help construct that site. "Research examining the concept of affordances [of technological tools] is critical if we are to build a science of distributed intelligence and a more flexible design orientation to the practices of education" (Pea 1997, p. 51). Design of the DCR environment was based on philosophical assumptions of social constructivism and on 
distributed cognitions theory with the intention of supporting collaborative knowledge construction among members of a caring community. The qualitative methods used to investigate the overall impact of the Website, particularly of its affordances for collaborative knowledge construction, extended the research on use of technologies to support social constructivist learning.

Third, findings in this study inform design and support grounded theory for design and development of read/write Web learning environments. Design-development guidelines generated are evidence-based and are generalizable to other design efforts because they are based upon reflective process analysis rather than the summative effects of a contextualized intervention (Wang and Hannafin 2005). They are of practical use for read/write Web developers and could not be generated through traditional experimental research approaches. We have provided detailed confirmatory evidence that the DCR achieves its goal by reaching out to the broad disability community to increase disability awareness as predicted by its social constructivist and distributed cognitions framework.

Fourth, other states can develop their own DCR given our lessons learned, the source code for the DCR, a server, and minimal human resources. Now that the Website is fully developed and has achieved the goal of outreach to the disability community in Texas, further research needs to be conducted to determine how successfully the community maintains the read/write environment's service and keeps it accurate and up-to-date. Theoretically, read-write Web technologies function through collaborative creation of content "where knowledge is shaped and acquired through a social process" (Richardson 2006, p. 126). The DCR's success utterly depends upon active participation by the community. We have carefully designed the DCR so that the community can easily maintain the site. Now we need to establish that community maintenance does sustain the site over time and identify the conditions under which such community maintenance works.

Evidence of the DCR's effectiveness and validation of the design and development guidelines will be further provided if and when other states adopt the read/write approach to develop their own disability directories and apply the guidelines proposed here. Application of the guidelines for read/write design and development in contexts other than disability directories would provide further evidence of their validity. This design and development research has the potential to meet educators' and instructional designers' needs and to influence practice. The DCR demonstrates that read/write Web technologies can be used to harness the community to collectively create high quality services entrusted to only a few in the past.

Acknowledgements This work was funded by the Center on Disability and Development at Texas A\&M University and the Texas Department of Aging and Disability Services.

\section{References}

Aronsson, L. (2002). Operation of large scale, general purpose wiki Website. In J. Á. Carvalho, A. Hubler, \& A. A. Baptista (Eds.), Proceedings of the 6th international ICCC/IFIP conference on electronic publishing (pp. 27-37). Karlovy Vary, Czech Republic: VWF Berlin.

Butler, D., Hogan, J., Hopkin, M., Peplow, M., \& Simonite, T. (2005). Internet encyclopaedias go head to head. Nature, 438, 900-901.

Carr, A. (1997). User-design in the creation of human learning systems. Educational Technology Research and Development, 45(3), 5-22.

Chen, I. (2001). Social constructivism. In An electronic textbook on instructional technology from http://coe.uh.edu/ ichen/ebook/ET-IT/social.htm. 
Collins, A., Joseph, D., \& Bielaczyc, K. (2004). Design research: Theoretical and methodological issues. Journal of the Learning Sciences, 13(1), 15-42.

Dede, C. (2004). If design-based research is the answer, what is the question? A commentary on Collins, Joseph, and Bielaczyc; diSessa and Cobb; and Fishman, Marx, Blumenthal, Krajcik, and Soloway in the JLS special issue on design-based research. Journal of the Learning Sciences, 13(1), 105-114.

Descy, D. (2007). All aboard the Internet: Getting your Website noticed. TechTrends, 51(5), 3-4.

Design-Based Research Collective. (2003). Design-based research: An emerging paradigm for educational inquiry. Educational Researcher, 32(1), 5-8.

Dorsey, L. T., Goodrum, D. A., \& Schwen, T. M. (1997). Rapid collaborative prototyping as an instructional development paradigm. In C. R. Dills \& A. J. Romiszowski (Eds.), Instructional development paradigms (pp. 445-466). Englewood Cliffs, NJ: Educational Technology Publications.

Drupal. (2008, December 1). Wikipedia, the free encyclopedia. Retrieved December 1, 2008, from http://en.wikipedia.org/w/index.php?title=Drupal\&oldid=259210551.

Ely, D. (1990). Conditions that facilitate the implementation of educational technology innovations. Journal of Research on Computing in Education, 23(2), 298-305.

Fosnot, C. T. (1996). Constructivism: Theory, perspectives, and practice. New York, NY: Teachers College Press.

Graham, J. (2004, December 14). Google's library plan “a huge help.” USA Today. Retrieved September 26, 2005, from http://www.usatoday.com/money/inductries/technology/2004-12-14-google-usat_x.htm.

Gustafson, K. L., \& Branch, R. M. (1997). Revisioning models of instructional development. Educational Technology Research and Development, 45(3), 73-89.

Halavais, A., \& Hernandez, P. (2004). Blogs, threaded discussions accentuate constructivist teaching. Online Classroom, 1.

Havelock, R., \& Zlotolow, S. (1995). The change agent's guide (2nd ed.). Englewood Cliffs, NJ: Educational Technology Publications.

Jansen, M. A., \& Smith, D. L. (1985). Prototyping for systems development: A critical appraisal. MIS Quarterly, 9(12), 305-314.

Jones, T. S., \& Ritchey, R. C. (2000). Rapid prototyping in action: A developmental study. Educational Technology Research and Development, 48(2), 63-80.

Lenhart, A., Horrigan, J. B., \& Fallows, D. (2004). Content creation online. Pew Internet \& American Life Project.

Lightner, S. B., \& Willi, C. (2007). Team-based activities to promote engaged learning. College Teaching, 55(1), 5-18.

Lincoln, Y. S., \& Guba, E. G. (1985). Naturalistic inquiry. Newbury Park, CA: Sage.

Liu, A. (2004). Transcendental data: Toward a cultural history and aesthetics of the new encoded discourse. Chicago, IL: University of Chicago.

McCarthy, M. G., \& Stough, L. M. (2000). The qualifying game: A search for services by individuals with disabilities. Education and Training in Individuals with Mental Retardation and Developmental Disabilities, 34, 485-498.

Morrison, G. R., Ross, S. M., \& Kemp, J. E. (2004). Designing effective instruction. Hoboken, NJ: John Wiley \& Sons.

Mullet, K., \& Sano, D. (1995). Designing visual interfaces: Communication oriented techniques. Englewood Cliffs, NJ: Prentice Hall.

Orrill, C. H., Hannafin, M. J., \& Glazer, E. M. (2003). Disciplined inquiry and the study of emerging technology. In D. H. Jonassen (Ed.), Handbook of research for educational communications and technology (2nd ed., pp. 335-353). Mahwah, NJ: Lawrence Erlbaum Associates.

Pea, R. D. (1997). Distributed intelligence and designs for education. In G. Salomon (Ed.), Distributed cognitions: Psychological and educational considerations (pp. 47-87). Cambridge, UK: Cambridge University Press.

Reeves, T. (2000, November-December). Socially responsible educational technology research. Educational Technology, 19-28.

Resch, J. A., Mireles, G., Benz, M. R., Zhang, D., Peterson, R. L., \& Grenweldge, C. (2009). Giving parents a voice: A qualitative study on the challenges parents of children with disabilities experience. Manuscript submitted for publication.

Richardson, W. (2006). Blogs, wikis, podcasts, and other powerful Web tools for classrooms. Thousand Oaks, CA: Corwin Press.

Richey, R. C., \& Klein, J. D. (2007). Design and development research. Mahweh, NJ: Lawrence Erlbaum Associates.

Salomon, G. (Ed.). (1994). Distributed cognitions. Cambridge, UK: Cambridge University Press. 
Spector, J. M. (2005). Innovations in instructional technology: An introduction to this volume. In J. M. Spector, C. Ohrazda, A. Van Schaack, \& D. A. Wiley (Eds.), Innovations in instructional technology: Essays in honor of M. David Merrill (pp. xxxi-xxxvi). Mahwah, NJ: Lawrence Erlbaum Associates.

Strauss, A., \& Corbin, J. (1990). Basics of qualitative research: Grounded theory procedures and techniques. Newbury Park, CA: Sage.

Vygotsky, L. S. (1978). Mind and society: The development of higher psychological processes. Cambridge, MA: Harvard University Press.

Wang, F., \& Hannafin, M. J. (2005). Design-based research and technology-enhanced learning environments. Educational Technology Research and Development, 53(4), 5-23.

Lauren Cifuentes is Associate Professor in the Educational Technology Program at Texas A\&M University and Information Dissemination Coordinator for the Center on Disability and Development. She investigates design considerations for collaborative instructional environments, the powers of shared multimedia for enhancing learning, and visual message design.

Amy Sharp serves as the Associate Director at the Center on Disability and Development, Texas A\&M University. Community Education, parental/self advocacy concerning disability issues, family-school collaboration, and public policy are her areas of focus.

Sanser Bulu is a doctoral student in the Educational Technology Program in the Educational Psychology Department at Texas A\&M University. He develops online learning systems. His research focuses on educational use of various technologies including web 2.0 and hand-held devices.

Mike Benz is Professor and Chair in the Special Education Program at Texas A\&M University and Director of the Center on Disability and Development. He investigates issues related to improving secondary, transition, and postsecondary services and outcomes for youth with disabilities.

Laura M. Stough is Associate Professor of Educational Psychology at Texas A\&M University and Interdisciplinary Training Director at the Center on Disability and Development. Her areas of research include qualitative methodologies and the effects of disaster on individuals with disabilities. 